\title{
Albumin-Bilirubin Grade as a Three-Month Survival Predictor in Hepatocellular Carcinoma Patients after Initial Transarterial Chemoembolization (ALBI Grade Predicting Survival in HCC Treated With TACE)
}

Ummi Maimunah ${ }^{1 *}$, Andri Pramana Restu ${ }^{2}$, Iswan Abbas Nusi ${ }^{1}, \mathrm{Herrry}$ Purbayu ${ }^{1}$, Titong Sugihartono $^{1}, \mathrm{Ulfa}$ Kholili ${ }^{1}$, Budi Widodo ${ }^{1}$, Muhammad Miftahussurur ${ }^{1}$, Husin Thamrin ${ }^{1}$, Amie Vidyani ${ }^{1}$, Poernomo Boedi Setiawan ${ }^{1}$

${ }^{1}$ Gastroentero-Hepatology Division, Department of Internal Medicine, Faculty of Medicine-Dr. Soetomo Teaching Hospital, Universitas Airlangga, Surabaya 60131, Indonesia

${ }^{2}$ Department of Internal Medicine, Faculty of Medicine-Dr. Soetomo Teaching Hospital, Universitas Airlangga, Surabaya 60131, Indonesia

\begin{abstract}
Article History:
Submitted: 25.02 .2020

ABSTRACT

One of hepatocellular carcinoma (HCC) therapeutic modality is transarterial chemoembolization (TACE). The albumin-bilirubin (ALB ) grade is amongst the newest of prognostic scores published to predic survival. The aim of this study was to analzye the ALBI grade as three-month survival predictor in HCC patients after initial TACE. This was a retrospective analytic observational study identifying patients that underwent initial TACE from January 2013 to December 2017 in Dr. Soetomo General Hospital, Surabaya. Data were collected before treatment and analyzed to evaluate $\mathrm{ALBI}$ grade as a survival predictor. Out of $134 \mathrm{HCC}$ patients, the subjects consisted of $100(74.6 \%)$ male subjects and $34(25.4 \%)$ female subjects. There were $25(18.7 \%), 98$ $(73.1 \%)$, dan $11(8.2 \%)$ subjects who were classified into to ALBI 1 $A L B I 2$, and $A L B I 3$, respectively, with a median ALBI score of -2.295 . The ALBI grade was significantly associated with the three-month
\end{abstract}

\section{INTRODUCTION}

Hepatitis B infection was the most common hepatitis infection in Indonesia. ${ }^{1} \mathrm{H}$ epatitis B diseases can lead to hepatocellular carcinoma (HCC). ${ }^{2}$ Transmission of HBV is parenteral, in contact with blood or other body fluids. ${ }^{3,4}$ In addition, intra-familial transmission is a potential source of HBV-infected patients. ${ }^{5}$ HBV acquisition in early life is mostly asymptomatic but associated with a particular risk of developing chronic infection. ${ }^{6}$

Hepatocellular carcinoma (HCC) is the most frequent primary liver cancer in patients with chronic liver diseases and cirrhosis.? HCC is the sixth most common cancer wolrdwide, and also the third leading cause of cancer-related death. 8,9 Other causes that can develop HCC are nonalcoholic fatty liver disease, aflatoxin, alcohol, and genetic factors. ${ }^{10}$

Highest incidence of HCC is detected in Southeast A sia and sub-saharan district of Africa in which hepatitis $B$ virus infection is endemic. Whereas, Hepatitis C virus (HCV) related HCC increases sharply in the United States. ${ }^{11,12}$ Prevalence rate of HCC in developing countries are twice the number of that in developed countries. The mortality rate in Asia and Africa are 33.5 and 23.73 per 100.000 people, respectively. ${ }^{13}$ The rate decreased to $2.8-4.7$ per 100.000 people in the last decade..$^{14}$ In Indonesia, HCC is one of the most common cancer in several hospitals, and the prevalence inclines each year. ${ }^{15}$

The main therapy of HCC is tumor resection, but most patients are not suitable candidates for surgery because of the tumor size or the impairment of liver function. Other therapeutic modality for inoperable patients is transarterial chemoembolization (TACE), which is a procedure of
Revised: 10.04 .2020

Accepted: 08.05 .2020

survival variable $(p=0.01 ; C I 95 \%)$. Using the ROC curve, we have determined a new cut-off point. The group of ALBI score $\leq-2.27$ had an odds ratio of 2.549 (Cl 95\% 1.232-5.273) for three-month survival. The ALBI grade was associated with three-month survival after initial TACE in patients with HCC

Keywords: HCC, TACE, ALBI grade, survival

Correspondance:

Ummi Maimunah, MD

Department of Internal Medicine, Faculty of Medicine-Dr. Soetomo Teaching Hospital, Universitas Airlangga, Surabaya 60131

Indonesia

Email: umima@gmail.com

DOI: $10.31838 /$ srp. 2020.531

@Advanced Scientific Research. All rights reserved

administrating cytotoxic and embolization to the cancer site. ${ }^{16}$ Patients with HCC that can receive optimal benefit from TACE are those who are classified in the Barcelona Classification of Liver Cancer (BCLC) B stadium. ${ }^{17}$

The mechanism of TACE is a combination of transarterial embolization and regional chemotherapy to produce ischemic necrosis and slow tumour progression. ${ }^{18,19}$ Several studies about TACE showed variable results on survival. One meta-analysis confirmed survival benefits of TACE and reported that the mean of thetwo-year survival percentage in the TACE group was higher than the control group (41\% vs $27 \%$ ), also the objective response related to TACE reached $35 \%$ (16-61\%). On the other hand, a cochrane analysis of six studies did not obtain any advantage on survival between TACE and the control group..$^{19}$ This variability was thought to be caused by the heterogenicity of patients with HCC. Therefore, patient selection is a crucial matter for TACE procedure to succeed. ${ }^{20}$ In selecting patient, various predictors that are related to survival after TACE, including laboratory parameters and scoring systems, had been studied. Of all the scoring systems tested, the albumin-bilirubin (ALBI) grade is acknowledged of having a better prognostic power compared to others. ${ }^{21-23}$

The ALBI grade is a new approach model to assess the prognosis of patients with HCC. This scoring system offers a simple, evidence-based, and objective method of assessing liver function that has been extensively tested in an international setting. The ALBI gradeutilizes only thelevel of serum albumin and serum bilirubin, which eliminates the necessity of subjective variables, such as ascites and encephalopathy used in child-pugh scoring. ${ }^{24} \mathrm{The}$ aim of this 
study was to analyze the ALBI grade as a survival predictor of three-month survival in HCC patients after initial TACE.

\section{MATERIALS AND METHODS}

This study used a retrospective analytic observation design and identified patients that underwent initial TACE from the $1^{\text {st }}$ of January 2013 to the $31^{\text {st }}$ of December 2017 in Dr. Soetomo General Hospital, Surabaya. Data on demography, laboratorium, and radiology were taken from patient's medical record. The diagnosis of HCC was based on the criteria from American Association for the Study of Liver Disease (AASLD). The exclusion criteria were incomplete data and if patient underwent second TACE before three month after the initial TACE. The decision of TACE was made by interdiscipline discussion with several considerations and was done in the radiointervention installation by a radiologist. Laboratorium data such as bilirubin serum and albumin serum were drawn before TACE to fulfill the study requirements. Before grouping patients into the ALBI grade, ALBI score must first be calculated using the formula of $=\left(\log _{10}\right.$ bilirubin $\left.\times 0.66\right)+$ (albumin $x-0.085)$. The ALBI score was then categorized into $3 A L B I$ grades, $\leq-2.60$ (ALBI 1), >-2.60 to $\leq-1.39$ (ALBI 2), dan >-1.39 (ALBI 3).

\section{Statistical Analysis}

Demographic data and clinical characteristic were presented descriptively, in frequency and percentage for categorical data. As for numerical data, authors used median or mean with standard deviation. All data were tested for normality using Shapiro-Wilk test. To analyze the association between two variables with nominal scales, chi-square test was used. If significancy was achieved, cross tabulation test was done to calculate odds ratio (OR). To compare differences between two groups, the $M$ ann-W hitney $U$ test was utilized because the data did not have normal distribution. Significancy was achieved if $p$ value $<0.05$. All statistical analyses were undertaken using the SPSS program for W indows version 23.0.

\section{RESULTS}

The subjects' baseline characteristics are shown in Table 1 . The total subjects of this study were 134 patients with HCC after initial TACE, consisting of 100 (74.6\%) male subjects and $34(25.4 \%)$ female subjects. The median age was 52 years with age ranging from 21 to 77 years. As many as 88 (65.7\%) subjects had normal level of albumin serum, and the mean of albumin serum was $3.56 \mathrm{mg} / \mathrm{dL}$. There were 47 (35.1\%) subjects with eleveated total bilirubin, and the mean was 1.22 $\mathrm{g} / \mathrm{dL}$. After calculating the ALBI score, the mean was -2.18. According to the $A L B I$ grade, the number of patients in the ALBI 1, ALBI 2, and ALBI 3 were 25 (18.7\%), 98 (73.1\%), and $11(8.2 \%)$, respectively. After three months post initial TACE, the majority of subjects (64.2\%) still survived.
Tabel 1: Baseline Characteristics

\begin{tabular}{ll}
\hline Characteristics & Result $(\mathbf{n}=\mathbf{7 6})$ \\
\hline Age (years) & $52(21-77)$ \\
Sex & $100(74.6)$ \\
M ale & $34(25.4)$ \\
Female & $3.56 \pm 0.49$ \\
Albumin & $46(34.3)$ \\
$<3.5 \mathrm{~g} / \mathrm{dL}$ & $88(65.7)$ \\
$\geq 3.5 \mathrm{~g} / \mathrm{dL}$ & $1.22 \pm 0.74$ \\
Total Bilirubin & $87(64.9)$ \\
$0.2-1.2 \mathrm{mg} / \mathrm{dL}$ & $47(35.1)$ \\
$>1.2 \mathrm{mg} / \mathrm{dL}$ & \\
ALBI Score & $-2.18 \pm 0.52$ \\
mean \pm SD & $-2.295(-3.18-(-0.71))$ \\
median (range) & \\
ALBI Grade & $25(18.7 \%)$ \\
ALBI 1 & $98(73.1 \%)$ \\
ALBI 2 & $11(8.2 \%)$ \\
ALBI 3 & \\
3-month Survival & $86(64.2 \%)$ \\
Survivor & $48(35.8 \%)$ \\
Non-survivor & D
\end{tabular}

Data presented as mean \pm SD, median (range), and number (\%)

Table 2: Bivariate A nalysis of ALBI Grade with 3-month Survival after TACE

\begin{tabular}{llll}
\hline Variables & \multicolumn{2}{l}{ Threemonth survival } & \\
\cline { 2 - 3 } & $\begin{array}{l}\text { Survivor } \\
(\mathbf{n = 8 6 )}\end{array}$ & $\begin{array}{l}\text { Non-survivor } \\
(\mathbf{n}=\mathbf{4 8})\end{array}$ & Pvalue \\
\hline Grade of ALBI & & & 0.01 \\
ALBI 1 & 20 & 5 & \\
ALBI 2 & 63 & 35 & \\
ALBI 3 & 3 & 8 & \\
\hline
\end{tabular}

From bivariate analysis in Table 2, the A LBI Grade ( $p=0.01$; $\mathrm{Cl} 95 \%$ ) was significantly associated to the three-month survival variable. By comparing the groups in the ALBI grade as shown in Table 3, analysis resulted that some comparison was not significant, while others were significant but had a wide range of confidence interval. Authors then tried to analyze if there was any significant difference between the survivor and non-survivor groups, especially in regard to the ALBI score. Further analysis showed that the distribution of ALBI score $(p=0.003)$ differed significantly between the survivor and non-survivor groups. Following that result, ROC curve was used to determine a new cut-off point. Based on the curve, the new cut-off point was the ALBI score of 2.27. That cut-off point was utilized to establish new groupings in which would be analyzed to evaluate its association with the three-month survival variable. In Table 4, using the chi-square test, authors found that the new ALBI gradings were significantly associated with three-month survival ( $p=0.011 ; \mathrm{Cl} 95 \%)$. The group with an ALBI score $\leq$ -2.27 had an odds ratio of 2.549 ( $\mathrm{Cl} 95 \%$ 1.232-5.273) for three-month survival, meaning that HCC patients having ALBI score below -2.27 had 2.5 times the tendency of surviving three months after initial TACE than the other group (ALBI score >-2.27) 
Table 3: Bivariate Analysis of Groups in ALBI Grades with Three-month Survival after TACE

\begin{tabular}{|c|c|c|c|c|}
\hline \multirow[b]{2}{*}{ ALBI Grades } & \multicolumn{2}{|c|}{ Three-month survival } & \multirow[t]{2}{*}{ pvalue } & \multirow{2}{*}{$\begin{array}{l}\text { Odds Ratio } \\
\text { (CI 95\%) }\end{array}$} \\
\hline & $\begin{array}{l}\text { Survivor } \\
(n=86)\end{array}$ & $\begin{array}{l}\text { Non-survivor } \\
(\mathrm{n}=\mathbf{4 8})\end{array}$ & & \\
\hline ALBI 1 & 20 & 5 & 0.067 & $2.606(0.910-7.466)$ \\
\hline ALBI $2 \& 3$ & 66 & 43 & & \\
\hline ALBI $1 \& 2$ & 83 & 40 & 0.008 & $\mathbf{5 . 5 3 3}(1.393-21.983)$ \\
\hline ALBI 3 & 3 & 8 & & \\
\hline ALBI 1 & 20 & 5 & 0.134 & $2.222(0.767-6.437)$ \\
\hline ALBI 2 & 63 & 35 & & \\
\hline ALBI 2 & 63 & 35 & 0.017 & $4.800(1.196-19.266)$ \\
\hline ALBI 3 & 3 & 8 & & \\
\hline ALBI 1 & 20 & 5 & 0.002 & $10.667(2.049-55.516)$ \\
\hline ALBI 3 & 3 & 8 & & \\
\hline
\end{tabular}

Tabel 4: Bivariate A nalysis of the New ALBI Grade with 3-month Survival after TACE

\begin{tabular}{|c|c|c|c|c|}
\hline \multirow[b]{2}{*}{ Variables } & \multicolumn{2}{|c|}{ 3-month survival } & \multirow[t]{2}{*}{ pvalue } & \multirow{2}{*}{$\begin{array}{l}\text { OddsRatio } \\
\text { (CI 95\%) }\end{array}$} \\
\hline & $\begin{array}{l}\text { Survivor } \\
(n=43)\end{array}$ & $\begin{array}{l}\text { Non-survivor } \\
(n=44)\end{array}$ & & \\
\hline \multicolumn{5}{|l|}{ New ALBI Grade, $n$} \\
\hline ALBI score $\leq-2.27$ & 52 & 18 & 0.011 & $2.549(1.232-5.273)$ \\
\hline ALBI score > -2.27 & 34 & 30 & & \\
\hline
\end{tabular}

\section{DISCUSSION}

In the current study, the ALBI grade was significantly associated to three-month survival after initial TACE. The result was similar to other studies which indicated that the ALBI grade was an accurate prognostic model for HCC patients undergoing TACE. ${ }^{22}$ The ALBI grade as a potential survival predictor was reported to be a great model to represent liver function. ${ }^{25}$ Even in high-risk HCC patients, the ALBI grade was an accurate metrics of survival. ${ }^{21}$

Besides the ALBI grade, the ALBI score itself was also a significant predictor of overall survival ${ }^{26} A$ fterwards, authors analyzed the ALBI score between the survivor and nonsurvivor groups, and the result showed that the median of ALBI score $(p=0.003)$ differed significantly between the two groups. U sing the ROC curve, authors obtained a new cut-off point of -2.27 from the ALBI score. By utilizing the new cutoff point, a significant association and odds ratio was gained. This result indicated that the ALBI score has a more distinctive feature than the ALBI grade with its original cutoffs.

In this study, most of the subjects were male (74.6\%), and the median age was 52 years (range of 21-77 years). Several studies showed that the number of male subjects was higher than the female subjects with a variable ratio around 2:1 to 8:1. ${ }^{27}$ Whereas, the median age was slightly different compared to studies held in China with median age of 55-59 years and Europe with median age of 63-65 years. ${ }^{11}$

Majority of subjects were included in the ALBI 2 group (73,1\%). This result was similar to previous studies which subjects were mainly categorized as A LBI 2. ${ }^{22,25}$ The median of ALBI score was -2.295 , which was adjacent to the study in Tai wan with a median of $-2.49 .{ }^{25}$

This study has several weaknesses. It was only a single centre study with retrospective design, and data were retrieved form medical records. This new cut-off point should be tested in future studies with bigger samples, more predictor variables, with a prospective cohort design, and also longer evaluation period to confirm its ability to predict survival.

\section{CONCLUSION}

In conlcusion, the ALBI grade was associated with three month survival after initial TACE in patients with HCC. By using the ALBI score, we determined a more discriminating cut-off point for the population and concluded that patients with an ALBI score below the new cut-off point had better odds of surviving a three-month period after inital TACE.

\section{CONFLICT OF INTEREST}

The authors in this study declared that they do not have any conflict of interest with respect to this manuscript.

\section{REFERENCES}

1. Annisa, Zain LH, Loesnihari R. Protection status against hepatitis $B$ infection assessed fromanti-HBs level, history of vaccination andhistory of infection based on anti-HBc in medical students. In: $\mathrm{Vol} 125$. Institute of Physics Publishing; 2018. doi:10.1088/1755-1315/125/1/012104

2. Putera EM, Marcia D, Firdarini I, et al. Hepatitis B Serology Profiles On Children Aged 1-13 Years O Id In Sumenep, Madura. Indones J Trop Infect Dis. 2012;3(2):61-64. doi:10.20473/ijtid.v3i2.202

3. Tanadi MR, Lusida MI, Joewono HT. Proportion of HBsA g AN D H BeA g Positive In M aternal Patients A nd Their HBsAg Positives Babies With Immunoprophylaxis Of $\mathrm{Hbv}$ Immunization In Dr. Soetomo General Hospital, Surabaya. Indones J Trop Infect Dis. 2017;6(4):79-83. doi:10.20473/ijtid.v6i4.1372

4. Lubis H P, Halim B, Adenin I, Rusda M, Prasetiawan E. $H$ epatitis $B$ virus infection on male partner has negative 
impact on in-vitro fertilization. In: IOP Conference Series Earth and Environmental Science. Vol 125. Institute of Physics Publishing; 2018. doi:10.1088/1755-1315/125/1/012045

5. Gunardi H, Iskandar MY, Turyadi, et al. Hepatitis B virus infection in children of $\mathrm{HBV}$-related chronic liver disease patients: a study of intra-familial HBV transmission. Hepatol Int. 2017;11(1):96-104. doi:10.1007/s12072-016-9764-z

6. Darmawan E, Turyadi, El-Khobar KE, Nursanty NKD, Thedja MD, Muljono DH. Seroepidemiology and occult hepatitis $B$ virus infection in young adults in Banjarmasin, Indonesia. J Med Virol. 2015;87(2):199207. doi:10.1002/jmv.24045

7. Bruix J, Sherman M. M anagement of Hepatocellular Carcinoma: An Update. J Hepatol. 2011;53(3):1020_ 1022. doi:10.1002/hep.24199

8. Torre LA, Bray F, Siegel RL, Ferlay J. Global Cancer Statistics, 2012. Ca Cancer J Clin. 2015;65(2):87-108. doi:10.3322/caac.21262.

9. Njei B, Rotman Y, Ditah I, et al. Emerging Trends in Hepatocellular Carcinoma Incidence and Mortality. Hepatology. doi:10.1002/hep.27388.Emerging

10. Siregar GA, Buulolo BA. Factors associated with tumor size of hepatocellular carcinoma. In: IOP Conference Series Earth and Environmental Science. Vol 125. Institute of Physics Publishing; 2018. doi:10.1088/1755-1315/125/1/012137

11. El-Serag HB. Hepatocellular carcinoma. N Engl J M ed. 2011;365(12):1118-1127. doi:10.1056/N EJM ra1001683

12. Petrick JL, Kelly SP, Altekruse SF, McGlynn KA, Rosenberg PS. Future of Hepatocellular Carcinoma Incidence in the U nited States Forecast Through 2030. J Clin Oncol Off J Am Soc Clin Oncol. 2016;34(15):1787-1794. doi:10.1200/JC0.2015.64.7412

13. Bosch FX, Ribes J, Díaz M, Cléries R. Primary liver cancer: worldwide incidence and trends. Gastroenterology. 2004;127(5 Suppl 1):S5-S16. doi:10.1053/j.gastro.2004.09.011

14. Bugianesi E. Non-alcoholic steatohepatitis and cancer. Clin Liver Dis. 2007;11(1):191-207, x-xi. doi:10.1016/j.cld.2007.02.006

15. Kementerian Kesehatan RI. Riset Kesehatan Dasar 2013. Jakarta: Badan Penelitian dan Pengembangan Kesehatan Departemen Kesehatan Republik Indonesia; 2013. doi:10.1007/s13398-014-0173-7.2

16. Lencioni R. Chemoembolization in patients with hepatocellular carcinoma. Liver cancer. 2012;1(1):4150. doi:10.1159/000339019

17. Burrel M, Reig $M$, Forner $A$, et al. Survival of patients with hepatocellular carcinoma treated by transarterial chemoembolisation (TACE) using Drug Eluting Beads. Implications for clinical practice and trial design. J Hepatol. 2012;56(6):1330-1335. doi:10.1016/j.jhep.2012.01.008

18. Au JS, Frenette CT. Management of Hepatocellular Carcinoma: Current Status and Future Directions. Gut Liver. 2015;9(4):437-448. doi:10.5009/gnl15022

19. Piscaglia F, Ogasawara S. Patient Selection for Transarterial Chemoembolization in Hepatocellular Carcinoma: Importance of Benefit/Risk Assessment. Liver cancer. 2018;7(1):104-119. doi:10.1159/000485471

20. Sieghart W, Hucke F, Peck-Radosavljevic $M$. Transarterial chemoembolization: Modalities, indication, and patient selection. J Hepatol. 2015;62(5):1187-1195.

21. Hansmann J, Evers MJ, Bui JT, et al. Albumin-Bilirubin and Platelet-Albumin-Bilirubin Grades Accurately Predict Overall Survival in High-Risk Patients Undergoing Conventional Transarterial Chemoembolization for Hepatocellular Carcinoma. J Vasc Interv Radiol. 2017;28(9):1224-1231.e2. doi:10.1016/j.jvir.2017.05.020

22. Ho S, Liu P, Hsu C, et al. Prognostic Role of Noninvasive Liver Reserve Markers in Patients with Hepatocellular Carcinoma undergoing Transarterial Chemoembolization. PLoS One. 2017;(Cdi):1-13.

23. Campani C, Vitale A, Dragoni G, et al. The ALBI and p-ALBI grades predict survival in patients with hepatocellular carcinoma undergoing transarterial chemoembolization (TACE). Dig Liver Dis. 2018;50:44. doi:10.1016/j.dld.2018.01.043

24. Johnson PJ, Berhane S, Kagebayashi C, et al. Assessment of Liver Function in Patients With Hepatocellular Carcinoma: A New Evidence-Based Approach - The ALBI Grade. J Clin Oncol. 2015;33(6):550-557. doi:10.1200/JC0.2014.57.9151

25. Lo C-H, Liu M-Y, Lee M-S, et al. Comparison Between Child-Turcotte-Pugh and Albumin-Bilirubin Scores in Assessing the Prognosis of Hepatocellular Carcinoma After Stereotactic Ablative Radiation Therapy. Int J Radiat Oncol Biol Phys. 2017;99(1):145-152. doi:10.1016/j.ijrobp.2017.04.036

26. M urray LJ, Sykes J, Brierley J, et al. Baseline albuminbilirubin (ALBI) in Western patients with hepatocellular carcinoma treated with stereotactic body radiotherapy (SBRT). Int J Radiat Oncol Biol Phys. 2018;101(4):900-909. doi:10.1016/j.ijrobp.2018.04.011

27. Buch SC, KondraguntaV, Branch RA, Carr BI. Genderbased outcomes differences in unresectable hepatocellular carcinoma. Hepatol Int. 2008;2(1):95101. doi:10.1007/s12072-007-9041-2 